https://helda.helsinki.fi

\title{
Emotions, values, and aesthetic perception
}

\section{Määttänen, Pentti}

2017-12

Määttänen , P 2017 , ' Emotions, values, and aesthetic perception ' , New Ideas in

Psychology, vol. 47 , pp. 91-96 . https://doi.org/10.1016/j.newideapsych.2017.03.009

http://hdl.handle.net/10138/300354

https://doi.org/10.1016/j.newideapsych.2017.03.009

cc_by_nc_nd

acceptedVersion

Downloaded from Helda, University of Helsinki institutional repository.

This is an electronic reprint of the original article.

This reprint may differ from the original in pagination and typographic detail.

Please cite the original version. 
New Ideas in Psychology

10.1016/j.newideapsych.2017.03.009

Emotions, values, and aesthetic perception

Pentti Määttänen

Abstract. Philosophical naturalism is a suitable background for an account of aesthetic perception as an alternative to traditional aesthetic theory. Pragmatist notion of habits as meanings gives a basis for a conception of emotions and values in the framework of organism environment interaction. Any object of perception may be a carrier of meanings if some habits are involved. This holds for linguistic expressions as well as for tones of color, doors and windows, museums, galleries and other non-linguistic sign-vehicles. The outcome is a multilayered system of meanings with which aesthetic perception is interpreted.

\section{Introduction}

Aesthetics emerged as a theory of fine arts, specific skills for creating beautiful experiences. The basic concept is that of disinterested pure beauty. It suits for the purpose of detaching aesthetic perception from everyday life with its interests. Museums, galleries and concert halls were constructed as special places for pure aesthetic contemplation. The interest in fine arts served well for the development of the life style of the new social stratum, real fine gentlemen, as becomes clear from one proposal to the name of these special skills: polite arts for polite people. (Mortensen 1997; Shiner 2001.)

John Dewey's book Art as Experience deals with the same topic. It should be noted, however, that his philosophical framework is completely different. Traditional aesthetics was formed within German idealism, which Dewey rejected at some point of his career. This fact is often ignored when commenting or developing his later work. In his philosophy of art Dewey uses the same word "esthetic" (with the difference of one letter) but the concept is not the same. Dewey's philosophical naturalism is the framework for developing an alternative conception of the experiences typical in (but not restricted to) fine arts. In one sense naturalism is a direct opposite of Immanuel Kant's overall view. According to Kant, the pure forms of sensibility and the pure concepts and categories of human understanding constitute nature as an object of possible knowledge. Naturalism, on the other hand, regards the human mind and human culture as a product of nature. All cognitive capacities and cultural phenomena have developed on this planet without any help from over and above nature. This entails that mind is necessarily embodied, and this has consequences also in aesthetic theory (see Scarinzi 2015).

There are, however, different forms of naturalism. The most common form can be called hard naturalism because of its appeal to (hard) natural science and reductionism (or mind/brain identity) in philosophy of mind (Määttänen 2006). John Dewey's naturalism is different. Culture is a product of nature, and there is no $a$ priori commitment to natural scientific methods. He sees science as problem solving. His answer to the 
question of what methods should be used, what operations should be performed, is simple: "the nature of the problem" (Dewey 1984, 99). Dewey applied this topic sensitive approach also in his aesthetic theory. The problem is this. How can one give an account of the undeniably enjoyable and emotionally powerful experiences produced by music, paintings, poetry and the like without committing oneself to presumptions rejected in naturalism? These experiences may be called aesthetic experiences, but in Dewey's framework it is conceptualized differently. This may sometimes lead to misinterpretations if one is not careful about the philosophical presumptions.

Dewey's soft naturalism shows also the way out of mind/brain identity with its commitment to the dichotomy of internal and external. He criticized the reflex arc concept because it tends to separate the body from its environment and suggested the notion of sensorimotor circuit instead (Dewey 1975b). This is a way to put emphasis on organism environment interaction. Combined with the pragmatist idea that the notion of experience as sense perception is too narrow, the role of action must be included, we get the view that interaction is realized through the loop of perception and action and that mind is a property of this loop rather than a property of the brain or even the body (Määttänen 2015b).

The social and cultural reality is an essential element in the environment of human beings. Soft naturalism with the emphasis on interaction helps to find out the role of cultural factors in aesthetic perception. Not everything is revealed by investigating the brain. This is not to diminish the value of brain imaging or other methods of brain research. The point is that the same findings may have different interpretations in different conceptual frameworks. The purpose of the following analysis of the structure of experience and the character of values and emotions in the light of this structure is to provide a coherent conceptual framework for the analysis of aesthetic perception.

\section{The structure of experience in pragmatism}

The traditional view in philosophy is that experience is sense perception. Sense organs function as channels through which the internal mind observes the external world. Visual perception has dominated the discussion since it was discovered that the eye functions like a camera obscura. The retinal image was thought to continue to the brain and to change into a mental image. This view was originally developed by Johannes Kepler, Leonardo da Vinci and René Descartes (Noë 2004, 35-48). Classical empiricism adopted this approach. "The senses at first let in particular ideas, and furnish the yet empty cabinet" (Locke 1959, I, 48; emphasis in the original). David Hume considered the possibility that perceptions are produced by external objects and came to this conclusion. "But here experience is, and must be entirely silent. The mind has never anything present to it but the perceptions, and cannot possibly reach any experience of their connection with objects" (Hume 1975, 153). The object of knowledge in this kind of approach is the external world as the hidden cause of perceptions. The hidden causes as such cannot, of course, be perceived, and therefore the task of the experiencing subject is to find out what we can really know about these hidden causes. They form the mind-independent real world that we must come to know.

This dichotomy of internal and external established by Descartes, Locke and their followers is still influential. Contemporary discussion continues this line of thought in attempts to relate mind and brain to each other. The mind/brain is internal quite literally. However, it has its critics that represent alternative 
view. For example, it has been criticized for a mereological fallacy. Mental predicates are properly attributed to behaving persons, not to a part of them, namely the brain (Bennett \& Hacker 2003, 68-107). This fallacy stems from Descartes. What Descartes said about the soul, is said about the brain.

The dichotomy of external and internal can be questioned. Antonio Damasio (1995) enlarges the analysis from the brain to the whole body. Andy Clark and David Chalmers (1998) started the discussion about extended mind, which refers to the need to take things outside the brain into account. Further, there is a close connection between action and perception as Dewey already pointed out. "While the optical apparatus may be isolated in anatomical dissection, it never functions in isolation. It operates in connection with the hand in reaching for things and in exploring their surface, in guiding manipulation of things, in directing locomotion" (Dewey 1980, 100; emphasis in the original). Nowadays there is plenty of empirical evidence for it (Lakoff \& Johnson 1999; Noë 2004). Visual perception selects properties that facilitate organism environment interaction (Gibson 1979; Rizzolati \& Sinigalia 2008). The environment becomes objectified in relation to motor capacities (Franks 2010,88). There is not any gap or dualism between acting and reasoning in intelligent behavior (Caruana \& Cuccio 2016). Various versions of enactivism (since Varela et al., 1992) also emphasize organism environment interaction. The role of interaction has found its way also to aesthetic theory (Xenakis, Arnellos \& Darzentas 2011; Xenakis \& Arnellos 2015). The main difference between these views and the present pragmatist approach is the explicit notion of meaning as habit of action.

The pragmatist alternative to the classical approach is based on the ideas of Charles Peirce and John Dewey (see Määttänen 2015b). The pragmatist notion of experience is broader than sense perception; action must be included in it. The world is experienced as possibilities of action. To know is to know what to do in the present situation in order to achieve some goal. This view about the structure of experience opens the possibility for a very different conception of mind. Action and perception form a loop or a cycle that characterizes organism environment interaction. On this view mind is a property of this loop as a whole rather than a property of the brain or even the body. There are, however, different forms of pragmatism. Not everyone agrees with this view (see Hildebrand 2003, Määttänen 2010).

The basic notion is that of habit of action. Habits are schematically structured forms or ways of action that are formed when similar behavior is repeated in similar circumstances. Action accommodates to objective conditions of action. The result of this is that the schematic structure of the formed habit fits with the objective conditions of action, the structure of the world. The habit is a belief about these conditions, and the fit between this belief and that what it is about is operational (Määttänen 2015b, 29-39). Note that this definition applies to both the physical and the social environment. Habits function also as meanings (ibid., 41-50). What a thing means is simply what habits it involves. Any object of perception may be a carrier of meaning, a sign-vehicle. All that is required is that some habits are involved. By virtue of habitual action, the object refers to anticipated consequences of that habitual action associated with the thing in question on the ground of past experiences of acting in similar circumstances. Note that this definition provides both tacit (non-linguistic) meanings and linguistic meanings. Ludwig Wittgenstein's principle that meaning is use is a specific instance of Peirce's definition (Määttänen 2005a). To be conscious is to be aware of various courses of action that are available. At the level of tacit meanings this is, for example, anticipation of the consequences of using tools, chairs, doors and so on. Abstract thought with language and scientific theories shows connections that are not immediate and thus enables one to anticipate more sophisticated operations and to see further and deeper. Thinking with meanings (and beliefs) is basically anticipation of action that is based on earlier experience. 
The simple definition of habit as an outcome of repeated similar behavior in similar circumstances may hide the fact that experience is a complex thing. Long experience during the whole biological evolution has equipped us with many skills and capacities for coping with the environment. Sense organs can be seen as crystallized habits of perceiving environmental cues relevant for action control. Most of these capabilities function subconsciously (Lakoff \& Johnson 1999; Franks 2010). The long history of cultural evolution has also accumulated social structures, cultural habits and practices. The relation between natural and cultural evolution is not simple because the social environment has existed long enough to have had an effect on our biological heritage. Other animals cannot become full-fledged members of human society. And this holds also for human infants if they grow outside human community. This is related to a phenomenon called the social brain (Donald 2001, Franks 2010). An infant's brain gets wired for linguistic competence only in the context of a human linguistic community. This is the so-called Outside-Inside principle first suggested by L.S.Vygotsky. "The developmental rule is that symbolic thought first represents external action, and only later reconstructs it so that it will occur internally" (Donald 2001, 250). The outcome is what Donald calls a hybrid mind. The symbolic storage is in the environment and people equipped with the social brain can use these symbols, but nervous systems don't use symbols comparable to numbers or words. Both parties, symbols and social brains, function together and form the hybrid mind. Human mind is a joint outcome of both parties of interaction. This view questions the classical dichotomy of external and internal and fits well with the present approach (although Donald does not refer in any way to the pragmatist tradition in philosophy).

During ontogeny each individual, with her biological heritage, adopts some part of the culturally accumulated social experience. The outcome is a multilayered storage of experience that can be analyzed with the notion of habit of action. Anticipation of action is thinking with (tacit and linguistic) meanings that help to see the consequences of various courses of action. The object of knowledge is the relation between the present experiential situation and the future experiential situation, and this relation is mediated by controlled habitual behavior. This structure of experience is a suitable framework for analyzing the character of values and emotions.

\section{Emotions and values in pragmatism}

The traditional conception about the relationship between facts and values is the following. We can find out facts, how things are in the world, but values must be sharply distinguished from facts. Values are about how things ought to be or should not be. And it is a logical mistake, or so it is said, to try to infer values from facts. (Hume 1978, 468-469.) This conception is based on the view that experience is sense perception. The internal mind perceives with sense organs how things are in the external world, and one cannot literally perceive values "out there".

The problem with this conception is the erroneous conception of experience. The commitment to the dichotomy of external and internal also separates the internal mind from the external world of facts. However, philosophical naturalism does not allow of any immaterial mind. The body with its brain belongs to the material world. They are made of exactly the same stuff as the rest of the world. The stuff is only organized in a different way. Further, if we admit that action should be included in the notion of experience, then we cannot anymore content ourselves with what can be perceived at a given time. 
According to the view described above, the world is experienced as possibilities of action, and the acting agent is part of the world. This conception of the structure of experience results to a quite different view about the relationship between facts and values.

As said, the world is experienced as possibilities of action. In normal circumstances there are a great variety of these possibilities. It is impossible to carry out all the available possibilities at the same time. One simply has to choose. The choice is based on anticipation of action. Anticipation of action brings to mind what kind of consequences habitual action has had before. These consequences have some value for the acting agent. In other words, for an acting agent capable of habitual action, the perceived features of the environment refer (consciously or subconsciously) to anticipated consequences of action. In order to act one must choose, and the choice is based on the anticipated value of the future consequences. For an acting agent, facts and values are necessarily intertwined in experience. David Hume missed this point because of his conception of experience as sense perception. (Määttänen 2015b, 67-75; 2015c.)

Antonio Damasio (1995) has put forward the so-called somatic marker hypothesis according to which emotions are signs of values. This view fits well with the present version of pragmatism. Emotions are based on the values of the anticipated future experience to the acting agent. Anticipation proceeds with habits that function as meanings referring to the future experiences. Most of the cognition with tacit meanings is subconscious and cannot be accessed by introspection. This is due to the complex and multilayered character of experience, on the ground of which the anticipation of action proceeds. Biological evolution, cultural heritage, individual growth and education have all an influence on emotional reactions to the environment. The idea is that the outcome of the subconscious cognition becomes conscious as emotions that warn us about potential dangers and help to concentrate on how to achieve promising goals. As Damasio points out, emotions and rational cognition function together. Damasio's conception of emotions and values can be applied also to aesthetic perception.

\section{Aesthetic perception}

Aesthetics emerged as a theory of fine arts, skills of producing beautiful experiences. There are reasons why just these experiences were chosen as beautiful. Aesthetics is supposed to describe and explain why, what is peculiar about these experiences. Why are these experiences enjoyable, emotionally powerful? The idea of disinterested pure beauty was introduced to explain this. However, traditional aesthetics entertained philosophical background assumptions that can be questioned. The task of an alternative approach is to give a different explication of the phenomenon.

John Dewey's account of aesthetic experience is based on philosophical naturalism (Dewey 1980). As said, the same word gets a quite different content. Traditional aesthetics separated and isolated aesthetic experience from other experiences. Dewey searches for continuity with life in general. There is no need to speak about specific aesthetic emotions that would have little or nothing to do with emotions in general. The same emotional mechanisms are responsible for the enjoyable character of music, paintings and so on, but perhaps in a different way. Another difference is that Dewey does not appeal to beauty or sublime but gives a formal definition of an aesthetic experience. It is formal in the sense that it is independent of the content of the experience. The main requirement is that it is rather a goal than a means for other 
experiences. In order to get into a concert one usually gets a ticket buying experience before the concert, but it is usually not the reason why people go to concerts. The music experience is different. Further features that Dewey gives are the consummatory character of the aesthetic experience; something has come to an end. It has unity, is enjoyable, emotionally powerful and most importantly valuable for its own sake. "An object is peculiarly and dominantly esthetic, yielding the enjoyment characteristic of esthetic perception, when the factors that determine anything which can be called an experience are lifted high above the threshold of perception and are made manifest for their own sake" (Dewey 1980, 57). There is continuity, but there is also a difference, relative disinterestedness. Aesthetic experience remains at the level of perception. Aesthetic perception is not directly connected to everyday practices. As pointed out above, it is a goal rather than a means. This characterization is, however, relative in the sense that aesthetic experiences may be means for one's education and so on. That these experiences are not isolated from life in general is based on the fact that perception is always interpreted with meanings. And meanings are, in pragmatism, ultimately habits and practices. Also symbolic meanings expressed in language have their connection with tacit meanings. Interpretation with meanings is based on anticipation of action, but in aesthetic perception these anticipations are not actualized. The consummatory character of aesthetic perception is only a promise of actual consummation that is enjoyable in itself. This is relative disinterestedness. The connection with life is manifested also in the interplay of continuity and difference. Quite a variety of experiences may have aesthetic quality, a consummatory aspect.

Dewey's approach suits well for discussing everyday experience from the viewpoint of aesthetic perception (Määttänen 2005b). For example, a visit to Finnish sauna most certainly has a consummatory aspect that makes it enjoyable in itself. It makes also sense to say that the goal of product design is to find a good combination of functionality and aesthetic aspects, to create a user experience with aesthetic quality. Everyday aesthetics is a common theme in the field. However, Dewey's efforts to develop an alternative to traditional aesthetics are sometimes ignored. Yuriko Saito, for example, has written a book on the topic and comments also Dewey's views. According to Saito "most of us have had an aesthetic experience through adopting a disinterested attitude" (Saito 2007, 43). This is typical for traditional aesthetics. Dewey took distance to these views: “'Disinterestedness' cannot signify uninterestedness" (Dewey 1980, 257). Dewey does not separate aesthetic experience from the interests of everyday life. He rather seeks connections and continuity. The discussion about an experience (with the emphasis) as a special experience that is demarcated from the general flow of life (ibid., 35-57). Saito, on the other hand, is quite clear about the attitude to traditional aesthetics. The mission of everyday aesthetics is to follow the guide suggested by the traditional aesthetic regarding aesthetic attitude and disinterestedness" (Saito 2007, 244). There is a need to distinguish between everyday aesthetics as an extension of traditional theory with its philosophical presumptions and Dewey's attempt to redefine the whole framework of discussion.

The present pragmatist framework puts aesthetic perception in the context of organism environment interaction. The view of mind as a property of interaction entails that there is no need to appeal to literally internal representations in the brain. Meanings (thoughts, ideas) are relations (processes) between organisms, sign-vehicles and their referents. The brain functions with anticipatory mechanisms that enable the organism to cope with the natural and social environment. Experience is interaction, and its character depends on the parties of interaction, the human body and its environment. The mind is a hybrid not only in Merlin Donald's sense (analogue brain functioning together with the symbolic environment, linguistic community) but also in the sense that we are a joint product of natural evolution and cultural history. Nature and culture are not separate spheres beside each other. The natural and cultural elements of the 
human mind form a complex whole in the manner of the multilayered system of meanings and that of experience. This holds also for aesthetic perception.

\section{Emotions in aesthetic perception}

Emotional quality is probably one of the reasons why certain experiences were chosen to be beautiful. However, emotions in aesthetic perception, especially when listening to music, have been problematic in traditional aesthetic theory. Emotions in music don't have obvious and consciously identified objects that they would be of and about. Formalism is one way to deal with this aspect. Susanne Langer $(1942,1953)$ maintains that sounds in music are symbols that do not denote to anything, and the connection with emotions is based on form: musical forms resemble the forms of emotions, and this explains music's ability to evoke emotions. Peter Kivy's (1989) problem is the emotional quality of music itself. How can music be sad while it is a work of art external to the human mind, an inanimate thing? Kivy's solution is based on St. Bernard. The dog looks sad but need not be sad, and so it is with music. Kivy's problem is related to the classical dichotomy of internal and external discussed above. Physical world is external and mind, thoughts, experiences, emotions are internal. Correspondingly a work of art, even a piece of music, is a physical external entity that cannot have emotions. This view can be questioned. The alternative view considers experience as organism environment interaction.

John Dewey made the distinction between an object of art and a work of art. A work of art is for Dewey experience, as should be clear already from the title of his book Art as Experience. An object of art is a physical thing that can hang on a wall, but "[ $t$ ]he real work of art is the building up of an integral experience out of the interaction of organic and environmental conditions and energies" (Dewey 1980, 64). In other worlds, a work of art for Dewey is the object of art as experienced. Experiences differ from physical bodies in that their mode of existence is different. A physical body is an individual object that may have a specific location on a wall of a white cube. Experiences, on the other hand, exist as modes of organism environment interaction. Experiences cannot hang anywhere.

Dewey's distinction is deeper than it seems. Consider colors. It looks like the colors of a painting are its intrinsic physical properties, but strictly speaking the colors are the joint outcome of light, pigments on the canvas and the biological structure of an organism with eyes. In this sense colors are properties of organism environment interaction. It is misleading to speak about colors of a painting as physical properties of a physical object because nobody can look at a painting without having a visual experience of it. Dewey's distinction holds also for music. As physical entities sounds are just vibrations in a medium, like air. On the other hand, sounds are the effect of these vibrations on some organism with ears. Which one is music? In Dewey's view, a work of art is an object of art as experienced. If we accept this definition, then Kivy's problem vanishes. Music consists properly speaking of (actually or potentially) perceived, experienced sounds? Experience is always emotionally saturated, and this holds also for music. Vibrations in air form the object, but the work of art is these physical processes as experience. Dewey's distinction holds for every thinkable form of art because it is based on a general philosophical position concerning the character of experience with which Dewey rejects the basic background assumptions of traditional aesthetics.

Experience is the outcome of organism environment interaction, not something literally in the head. 
There is still the question of the role and character of emotions in aesthetic perception. Traditional aesthetics aims at separating aesthetic experience from everyday life with the notion of a special aesthetic emotion typical only for art (for example Bell 1958). Dewey's perspective searches connections with life and this holds also for emotions. Antonio Damasio's theories about emotions in general are helpful here. One of his basic principles is the somatic marker hypothesis according to which emotions are signs of values (Damasio 1995). If this is correct, then the question is the following. To what sort of values do emotions refer in aesthetic perception? Not surprisingly, Dewey's theory of emotion has a role here too (Dewey 1975a).

The general idea is that past experience involves accumulation of acquired habits that function as meanings, which refer to experienced consequences of habitual action. These consequences have been of some value. The present suggestion is that the outcome of subconscious cognition with habits as meanings becomes conscious as emotions that the past experiences have evoked. Let's start from the beginning, from biological evolution. Consider Dewey's summary of a phenomenon that he calls Gefühlston.

"Certain movements, formerly useful in themselves, become reduced to tendencies to action, to attitudes. As such they serve, when instinctively aroused into action, as means for realizing ends. But so far as there is difficulty in adjusting the organic activity represented by the attitude with that which stands for the idea or end, there is temporary struggle and partial inhibition. This is reported as Affect, or emotional seizure. Let the co-ordination be effected in one act, instead of in a successive series of mutually exclusive stimuli, and we have interest. Let such co-ordinations become thoroughly habitual and hereditary, and we have Gefühlston." (Dewey 1975a, 188.)

Any object of perception may be a carrier of meaning, and this holds also for colors and sounds. They refer subconsciously to the whole past experience as emotional seizure. The color red has a different Gefühlston than green or blue, and this is probably due to the past experiences related to these colors. Red has been related to fire, blood and maybe sexuality, that is, to stronger experiences than seeing the blue sky, for example. And sense organs as crystallized habits don't function in isolation. The ability to perceive certain properties has developed just because of the significance of these properties, and the emotional attitudes have developed during the same process. The Gefühlston of different aspects of perceived environment may well be an element in what makes up aesthetic quality, which can characterize perception not only in the context of fine arts.

Emotionally charged aesthetic quality has its sources in biological evolution. These emotions refer to accumulated past experiences. Habits as meanings explain this reference that cannot be accessed by introspection because of the role of subconscious mechanisms, habits crystallized as bodily organs, and tacit meanings, which control the relationship to the environment without the need of conscious attention. However, human beings are also cultural creatures. Soft naturalism combined with the view emphasizing the genuinely social character of human mind gives the possibility to examine the social and historical aspects related to aesthetic perception.

6. Aesthetic perception and the semiotics of space 
According to the semiotic theory of Charles Peirce the sign-relation is a three-place relation. A sign-vehicle refers to its object. The sign-vehicle must be interpreted to refer to the object, and therefore a third element, the interpretant, is required. An interpretant may be another sign-vehicle. If this is the case, then there has to be an interpretant for this sign-vehicle so that the requirement of a three-place relation is fulfilled. This interpretant may also be a sign-vehicle, which must be interpreted, and so the process of interpretation may continue to indefinite future. However, there is a special kind of interpretant, final logical interpretant to which the process of interpretation ends. This final logical interpretant is habit of action, which is actualized as acts in the world. This entails that habitual action is a way to interpret and understand the world. (Määttänen 2015b.)

For a pragmatist, the social reality exists as shared habits and practices, which are meaningful of their own right. Social practices may have definite locations. The practices are different, for example, in market place, church, cemetery, governmental palace, pub and so on. These different practices embody different meanings. The locations of these practices function as sign-vehicles, carriers of these meanings. (Määttänen 2007.) A special location for special practices is also the so-called white cube. The traditional aesthetic theory is not only written in books and journals. Museums, galleries, concert halls and opera houses are endowed with tacit and symbolic meanings that were created during the development of the practices and theories of fine arts. During this period paintings were transferred from homes to museums and galleries, music from courts to concert halls and opera houses. (Shiner 2001.) These places are special locations for the new social class with money and free time to carry on the practices of the contemplation of what was called disinterested pure beauty. These practices of fine art are meaningful in themselves, and the traditional aesthetic theory was created as a theory about these practices and experiences. The practices with meaningful locations and the theory support each other; they form a consistent system of tacit and symbolic meanings. These practices and locations in the urban space are still with us. So far as one participates in these practices one adopts (consciously or subconsciously) the meanings and goals (values) involved.

The point is that the place where perception takes place has an effect on how the perceptions are interpreted. The spatial semiotics is one element in the system of meanings with which we orient ourselves to the environment, how we experience it. This is one way to solve the problem of Brillo Box. What is the difference between a Brillo Box in a supermarket and a Brillo Box in Andy Warhol's show? Physically they are similar. Here we need again the distinction between an object of art and a work of art. The object may be the same, but the experience is different. When one enters gallery space the location functions as a sign-vehicle and brings to mind the adopted system of tacit and symbolic meanings that are related to the fine arts tradition (depending, of course, on ones education and other background). The Brillo Box in a gallery is interpreted with the meanings associated with the location and, of course, the artist's fame and the artworld as a whole. With the meanings come the corresponding values and emotions. The value of the box in gallery is loaded with the values of fine arts experiences. This is why there is a big difference between the values (and the prices) of these boxes. Meanings and values associated with other locations have also an effect on how art is experienced. A plan to present heavy metal music in a church may face resistance because two quite different systems of meanings and values are involved, and value conflicts arouse emotions, as one would expect.

7. Dimensions of aesthetic perception 
Perception is always interpreted with meanings acquired on the ground of past experience. The outcome of experience is a multilayered system of meanings based on different aspects of past experience. The sources of meanings are biological evolution, cultural history and individual experience during which one adopts some aspects of one's social and cultural environment with one's hereditary resources. Different people have different storage of meanings that is evolving all the time as life goes on. Habitual action is goaldirected activity based on anticipated experiential values, which arouse corresponding emotions. Most of this takes place subconsciously.

The basic emotional dimension of aesthetic perception is the emotional tone stemming from biological evolution, Dewey's Gefühlston. This tone of feeling is probably one of the reasons why certain skills were chosen as fine arts that produce beautiful experiences. There are certainly historical reasons as well. And the experienced Gefühlston is not independent of the influence of the later cultural elements in the accumulated experience. Because of its subconscious and possibly incoherent character it cannot be analyzed introspectively any further.

The emergence of the practice and theory of fine arts has left its trace in contemporary social environment and urban space. The social practices related to fine arts have traditionally been valued high in comparison with popular culture and everyday life. This appreciation shows itself as positive emotions associated with works of art. During socialization and education people adopt these values and emotional attitudes to certain extent that depends on how closely they are related to the practices. The conscious theoretical attitude is supported by the tacit meanings and values of spatial semiotics, which are often strengthened by appropriate (wow) architecture. This cultural dimension of aesthetic perception functions intertwined with the biological dimension.

The traditional aesthetic theory is still with us, but not only as a theory and presumptions of art criticism but also as tacit meanings tied to certain locations in the urban space. The philosophical framework of traditional aesthetics is only one strand in this whole. The rejection of this framework at the level of theory does not by itself change the already formed practices with the related meanings and values. It can, however, change our conception of these practices and their relation to other forms of life.

Dewey's definition is not based on specific concepts like beauty or sublime. According to him aesthetic experience has a unity, is consummatory and enjoyable, an end rather than a direct means to other experiences. It broadens the scope of the concept. Aesthetic appreciation is not a privilege of the traditional fine arts. There are other ways of producing aesthetic experience in Dewey's sense (witness his suggestion of "jazzed music" as art). Dewey's definition blur's the border between popular culture and fine arts. It is aesthetics of gender blender. And there is no need to separate aesthetic perception from other social practices. This sort of pluralism makes room for different genres and traditions with their own standards of taste. Especially there is no need to justify jazz or rap music as forms of art by appealing to the alleged fact that one can use in them the same criteria as traditional aesthetics in classical music, for example. The notion of aesthetic perception is a complex whole with many dimensions depending on the genre and its own traditions, social context and concrete location.

In soft naturalism culture is simply a product of nature, a system that one animal species has developed here on planet Earth. This view, combined with the idea of mind as a property of organism environment interaction, opens the possibility to take cultural and historical elements explicitly into account in analyzing 
the character of aesthetic perception. The difference between symbolic meanings (language) and tacit meanings as social practices with their sign-vehicles in urban space sheds light to the nuanced character of aesthetic perception.

There are three layers of experience as sources of habitual coping with the environment: natural evolution, cultural history and individual experience. Acquired habits function as meanings, tacit and symbolic, consciously or subconsciously. Basic emotional attitudes stem from biological inheritance. Social and cultural habits adopted during individual growth intertwine to this and the result is a whole where all aspects may have an effect to others. Aesthetic perception is situated. It is interpreted with a multilayered and complex system of meanings associated with different aspects of the situation: the object in focus, its qualities, and its location in physical and cultural environment. It is aesthetic by virtue of its consummatory character and relative disinterestedness.

References

Bell, C. (1958). Art. New York: Capricorn Books.

Bennett, M.R. \& Hacker, P.M.S. (2003). Philosophical foundations of neuroscience. Oxford: Blackwell.

Caruana, F., \& Cuccio, V. (2016). Overcoming the acting/reasoning dualism in intelligent behavior. Phenomenology and the Cognitive Sciences, doi:10.1007/s11097-016-9471-1.

Clark, A. \& Chalmers, D.J. (1998). The extended mind. Analysis, 58, 7-19.

Damasio, A. (1995). Descartes' error. Emotion, reason and the human brain. New York: Picador.

Dewey, J. (1975a). The theory of emotion. The early works 4 (pp. 152-188). Carbondale: Southern Illinois University Press.

Dewey, J. (1975b). The reflex arc concept in psychology. The early works 5 (pp. 96-109). Carbondale: Southern Illinois University Press.

Dewey, J. (1980). Art as experience. New York: Perigee.

Dewey, J. (1984). The quest for certainty. The later works 4. Carbondale: Southern Illinois University Press.

Donald, M. (2001). A mind so rare. The evolution of human consciousness. New York: W. W. Norton \& Company.

Franks, D. (2010). Neurosociology. The nexus between neuroscience and social psychology. New York: Springer.

Gibson J.J. (1979). The ecological approach to visual perception. Boston: Houghton Mifflin Company. Hildebrand, D. (2003). Beyond realism and antirealism: John Dewey and the neopragmatists. Nashville: Vanderbilt University Press. 
Hume, D. (1975). Enquiries concerning human understanding and concerning the principles of morals. Third edition. Oxford: Clarendon Press.

Hume, D. (1978). A treatise of human nature. Second edition. Oxford: Clarendon Press.

Kivy, P. (1989). Sound sentiment. An essay on the musical emotions. Including the complete text of The corded shell. Philadelphia: Temple University Press.

Lakoff, G. \& Johnson, M. (1999). Philosophy in the flesh. New York: Basic Books.

Langer, S. (1942). Philosophy in a new key. Cambridge: Harvard University Press.

Langer, S. (1953). Feeling and form. London: Routledge.

Locke, J. (1959). An essay concerning human understanding. New York: Dover Publications.

Mortensen, P. (1997). Art in the social order. The making of the modern conception of art. Albany: SUNY Press.

Määttänen, P. (2005a). Meaning as use: Peirce and Wittgenstein. In F. Stadler, \& M. Stöltzner (Eds.), Time and history. Papers of the $28^{\text {th }}$ international Wittgenstein symposium (pp. 171-172). Kirchberg am Wechsel: Austrian Ludwig Wittgenstein Society.

Määttänen, P. (2005b). Aesthetics of Movement and Everyday Experience, Contemporary Aesthetics, Special Volume 1. http://www.contempaesthetics.org/newvolume/pages/article.php?articlelD=347

Määttänen, P. (2006). Naturalism: hard and soft. In H. J. Koskinen, S. Pihlström, \& R. Vilkko (Eds.), Science A challence to philosophy? (pp. 227-236). Frankfurt am Main: Peter Lang.

Määttänen, P. (2007). Semiotics of space: Peirce and Lefebvre. Semiotica, 166, 453-461.

Määttänen, P. (2010). Shusterman on somatic experience. Action, Criticism \& Theory of Music Education, 9, 56-66.

Määttänen, P. (2015a). Emotionally charged aesthetic experience. In A. Scarinzi (Ed.), Aesthetics and the embodied mind: Beyond art theory and the Cartesian mind-body dichotomy (pp. 85-99). Dordrecht: Springer.

Määttänen, P. (2015b). Mind in Action. Experience and Embodied Cognition in Pragmatism. Cham: Springer. Määttänen, P. (2015c). Naturalism and normativity in pragmatism. In Ulf Zackariasson (Ed.) Action, belief and inquiry - pragmatist perspectives on science, society and religion (pp. 94-107). Nordic studies in pragmatism 3. Helsinki: Nordic Pragmatism Network.

Noë, A. (2004). Action in perception. Cambridge: The MIT Press.

Rizzolati, G. \& Sinigalia, C. (2008). Mirrors in the brain: how our minds share actions and emotions. Oxford: Oxford University Press.

Saito, Y. (2007). Everyday aesthetics. Oxford: Oxford University Press. 
Scarinzi, A. (Ed.) (2015). Aesthetics and the embodied mind: Beyond art theory and the Cartesian mind-body dichotomy. Dordrecht: Springer.

Shiner, L. (2001). The Invention of Art. A Cultural History. Chicago: The University of Chicago Press.

Xenakis, I., \& Arnellos, A (2015). Aesthetics as an emotional activity that facilitates sense-making: towards an enactive approach to aesthetic experience. In A. Scarinzi (Ed.), Aesthetics and the embodied mind: Beyond art theory and the Cartesian mind-body dichotomy (pp. 245-259). Dordrecht: Springer.

Xenakis, I., Arnellos, A., \& Darzentas, J. (2011). The functional role of emotions in aesthetic perception. New Ideas in Psychology, 30, 212-226. 